\author{
Assistant Professor Cong LI, PhD \\ E-mail: qdulc2016@163.com \\ School of Economics, Qingdao University \\ Professor Xi-hua LIU, PhD(Corresponding Author) \\ E-mail: xihua-liu@163.com \\ School of Economics, Qingdao University \\ Jiao WANG, Master \\ E-mail: hzjiaoer@163.com \\ School of Economics, Shanghai University \\ Lecturer Sorana VATAVU, PhD \\ E-mail: sorana.vatavu@e-uvt.ro \\ Department of Finance, West University of Timisoara \\ Associate Professor Anda Mihaiela IOSIF, PhD \\ E-mail: anda.iosif@e-uvt.ro \\ Department of Accounting and Audit \\ West University of Timisoara
}

\title{
FINANCIAL INCLUSION IN CHINA: HAS INPUT-OUTPUT EFFICIENCY IMPROVED?
}

Abstract. This paper evaluates whether the input-output efficiency of financial inclusion has improved or declined in China. The study's conclusions show that the input and output of financial inclusion are generally effective. However, the differences between regions are relatively large, the input-output levels of less developed regions are relatively low, and the static and dynamic efficiency of regions is relatively high. While technological progress and innovation have improved significantly, economic development, urbanization, government intervention, and information technologies have significantly affected input-output efficiency. This paper puts forward recommendations on ways of innovating financial products and services, developing digital financial inclusion, and optimizing the input structure of financial inclusion to promote the sustainable development of financial inclusion.

Keywords: financial inclusion, input-output efficiency, super-efficiency DEA, Malmquist index.

JEL Classification: C67, O1, G2

\section{Introduction}

This paper uses the super-efficiency data envelopment analysis (DEA) model and the Malmquist index to evaluate the input-output efficiency of financial inclusion and to determine if it improved or worsened after the implementation

DOI: 10.24818/18423264/55.2.21.03 
strategy of financial inclusion in China. Financial development can promote economic growth by improving the efficiency of resource allocation, and financial inclusion can effectively alleviate poverty and achieve inclusive economic growth (Gupte, 2012; Song et al., 2014). When financial development is not inclusive, low-income groups can only rely on their limited savings to start businesses or pay for education. Small businesses can then only rely on limited profits to expand their operations, which will lead to persistent income inequality and which is unconducive to long-term economic growth (Demirgüc, 2012). Moreover, by providing tools of financial risk management to individuals, families and small businesses, high-level financial inclusion development can have a positive impact on financial stability (Han et al., 2013). It is clear that financial inclusion is the prerequisite to ensuring the inclusiveness and sustainability of economic growth (Jiao et al., 2016). Therefore, the development of financial inclusion is regarded as an effective means to achieve economic growth and alleviate poverty in both developing and developed countries and has attracted considerable attention from scholars and policy makers in various countries (Wang \& Zeng, 2016). Despite several studies having been conducted on financial inclusion, which has multidimensional characteristics, different countries differ considerably in their economic, financial, and social development priorities, and development mechanisms of financial inclusion also vary ( $\mathrm{Lu}$ et al., 2019). In the midst of promoting the development of financial inclusion, means to evaluate and improve upon the efficiency of financial inclusion and to help economic entities enjoy and benefit from financial services have become a pressing issue in China.

According to the National Bureau of Statistics, China has a population of 1.383 billion and a rural population of 590 million, representing $43.66 \%$ of the country's total population in 2016. The level of financial services this population receives has centrally influenced the country's rural economy and social development. Therefore, Document No. 1 of the Communist Party of China (CPC) Central Committee proposed that financial inclusion focus on rural areas in 2018. Since December 2015, the State Council has executed a national strategy of financial inclusion based on The Plan for Promoting Financial Inclusion Development (2016-2020). Through active promotion from the government and financial institutions, financial inclusion in China has developed rapidly (Qi et al., 2019). The availability, use, and quality of financial services have also improved. Traditional financial products and services have been widely popularized. Information technologies are also profoundly changing the development model of financial inclusion (Lu et al., 2019; Ji et al., 2019). However, due to different levels of financial development and the varied operating efficiency of financial resources, an imbalance in financial inclusion services remains (Yang, 2018). As China's largest agricultural province, Shandong is home to a population of 49.84 million and generated the highest level of total production in 2017, making it a key province for developing financial inclusion. Shandong's economic structure is similar to that of the whole country (2018, Overall Scheme for the Construction of

DOI: $10.24818 / 18423264 / 55.2 .21 .03$ 
Financial Inclusion in China: Has Input-Output Efficiency Improved?

a Comprehensive Test Zone for New and Old Kinetic Energy Conversion in Shandong) and exhibits imbalances in regional development that are also highly consistent with those of China as a whole (i.e., disharmony and imbalances between eastern, central, and western regions; coastal and mainland regions; and urban and rural areas) (Zhang \& Wang, 2017). This paper takes Shandong Province as an example to study ways to efficiently develop financial inclusion, analyzes dynamic changes in the input-output efficiency of financial inclusion, and discusses whether input-output efficiency improve or worsen after implementation strategy application.

This paper fully considers the actual situation observed in Shandong Province, an economically and agriculturally typical province in China, to study financial inclusion from the perspective of input and output. In recent years, the government has made several positive efforts by introducing the "Several opinions of the Shandong Provincial People's Government on accelerating financial reform and development", "Implementation opinions on promoting the development of financial inclusion" and other policies. By adopting an index that can help Shandong Province build a financial inclusion index, this index can further help our government further financial reforms, establish and improve a multi-level financial inclusion system, and provide universal financial services for small and micro-scale enterprises and farmers. At the same time, such an approach will ensure balances financial inclusion development across localities and cities, promote the rational and effective allocation of financial resources, accelerate the good and rapid economic development of Shandong Province, and realize the region's coordinated development. The present work is thus of significance to research on the development of financial inclusion in Shandong Province and can be referenced to further the study of financial inclusion levels in other provinces.

The remainder of this paper is organized as follows. Section 2 briefly reviews the related literature. Section 3 provides an overview of empirical methodologies used to measure input-output efficiency and its dynamic trends. Section 4 presents our empirical findings. Section 5 presents conclusions and policy recommendations.

\section{Literature Review}

Financial inclusion promotes economic and social progress. The economic and social development of a country is positively related to financial benefits (Mandira et al., 2011). From cross-border data, Anand et al. (2013) find that the value of the human development index increases by $0.142 \%$ when financial inclusion increases by $1 \%$. Then, financial inclusion can improve the lives of the poor in terms of employment and income (Su et al., 2020). It can also narrow the gap between the rich and poor and reduce the Gini coefficient (Beck et al., 2009). In addition, financial inclusion improves a country's financial stability (Alam et al., 2018). First, financial inclusion can effectively promote economic growth (Yang, 2020). Then, financial inclusion can narrow the gap between urban and rural income and welfare levels (Xu et al., 2017; Li, 2019). Besides, financial inclusion

DOI: 10.24818/18423264/55.2.21.03 
is conducive to easing the financing difficulties of small and medium-sized microscale enterprises (Cheng, 2014; Su et al., 2020). The development of financial inclusion would also have a certain link to inflation, while the main concern for the monetary policy would be to maintain price stability. This would be supported by the regional development, although large differences and gaps across regions involve more heterogeneous inflation, with different perceptions and expectations. $\mathrm{Xu}$ et al. (2016) emphasised that educated agents and other demographic characteristics may lead to a more accurate expectation and perception of the economic conditions. However, the monetary authority has the best means of achieving price stability by anchoring the annual inflation within the established medium term limits, by maintaining a more prudent policy for economic growth (Khan et al., 2017).

The measurement of the development of financial inclusion is central to quantifying financial inclusion. Sarma (2008) draws lessons learned from the construction method of the United Nations Development Program's Human Development Index (HDI) and constructs the Financial Inclusion Development Index (IFI) from three dimensions, bank penetration, bank service availability, and usage, to measure the level of financial inclusion in various countries. Arora (2010) finds levels of financial inclusion in developed countries to be higher than those in developing countries. Chen et al. (2019) determine the weights of financial service penetration, availability, use effectiveness and affordability to measure China's provincial financial inclusion index. After the release of China's Financial Inclusion Index System, the Xining Central Sub-branch of the People's Bank of China found the effect of China's financial popularization to be very obvious and the gap between provinces in the development of inclusive finance to be narrowing. Sharma et al. (2018) develop a state index for financial inclusion through normalized inverse Euclidean distance using the per capital number of accounts, total balance, and number of debit cards.

Factors that influence financial inclusion have been a major focus of scholarship. Bester et al. (2018) believe that the unreasonable design of financial products, which makes it difficult to meet the needs of the poor, is a factor that affects levels of financial inclusion. Appleyard (2019) compares the distributions of financial institutions in poor areas of Britain and the United States and finds that financial service outlets are conducive to the development of financial inclusion. Mandira et al. (2011) believe that income, inequality, literacy rates, urbanization, and information infrastructure can significantly affect financial inclusion but that the stability of financial institution has no significant effect. Allen et al. (2012) find that educational background heavily affects the development of financial inclusion. Sharma et al. (2018) find the status of infrastructure to be the most significant determining factor. Due to the use of different research objects or methods of constructing financial inclusion indexes, factors proposed by scholars to influence financial inclusion development differ, but they mainly cover economic and financial factors, policies, education, and information factors (Zhang et al., 2017;

DOI: $10.24818 / 18423264 / 55.2 .21 .03$ 
Financial Inclusion in China: Has Input-Output Efficiency Improved?

Long et al., 2020). Among these factors, some affect inputs of financial inclusion, some affect outputs of financial inclusion, and some affect both inputs and outputs. Therefore, in this paper we argue that these factors will also affect the input-output efficiency of financial inclusion.

Related studies on China have mainly focused on the input-output efficiency of the financial industry or of financial institutions. For example, Du et al. (2016) argue that greater regional differences in input-output efficiency in technology and finance observed in China are due to soft environment factors such as investment environments and laws. Long et al. (2018) argue that regional differences in input-output efficiency should be determined from aspects of innovative technologies and finance products and by optimizing technology and finance investment channels. In addition to the DEA method, Zhang et al. (2011) use the Stochastic Frontier Approach (SFA) to analyze the efficiency of financial support for agriculture in Shanxi Province. The authors find that rural financial market concentration, intermediary efficiency, and development structures are the main factors that restrict the efficiency of financial support for agriculture. Farmers should also rely on technology and science to improve their production and become more efficient, as the Chinese agricultural commodity markets are very sensitive to international markets, especially for products on high demand such as garlic, ginger, or corn (Zhang et al. (2019). Accordingly, government should increase its supervision and minimise policy distortions to avoid market speculations for agricultural commodities. Chen et al. (2017) identify differences in industrial structures in relation to financial input-output efficiency. While financial support for the tertiary industry has remained high with stable input-output efficiency, the input-output efficiency of the secondary industry has greatly decreased. Based on the DEA-Tobit model, Zhang (2020) studies the efficiency of regional financial resource allocation and finds that economic development levels, industrial structure optimization levels, consumption efficiency, and location advantages can improve the efficiency of financial resource allocation while government intervention has negative effects.

Several scholars have used a variety of dimensional indicators to analyze the methods of financial inclusion measurement. However, there is no unified standard for the measurement of financial inclusion input-output efficiency. In China, research on financial inclusion input-output efficiency has become a major focus, but the selection of indicators rarely considers insurance and internet finance. At the same time, since financial innovation reforms were applied in Shandong Province in 2013, there has been a lack of empirical comparative research on financial inclusion levels. This paper uses the state of financial inclusion development in 17 cities in Shandong Province to build a financial inclusion system covering banking, insurance, agriculture-related loans, and small and micro-scale enterprise loans. The insurance density and penetration rate are also included in the index, and the amount of agriculture-related loans and small and micro-scale enterprise loans are used as a measurement index. While the

DOI: 10.24818/18423264/55.2.21.03 
traditional DEA method is used to measure the input-output efficiency of financial inclusion, it cannot evaluate effective decision-making units or adequately provide a specific ranking of various cities. Therefore, we first empirically investigate the super-efficiency levels of 17 cities in Shandong Province. We then analyze dynamic changes in input-output efficiency, estimate whether input-output efficiency improved or worsened after the implementation of financial inclusion, and analyze relevant influencing factors. Finally, we propose countermeasures and provide recommendations on ways to promote the financial inclusion in Shandong Province.

\section{Methodology}

\subsection{Super-efficiency DEA model}

Based on the concept of relative efficiency, Data Envelopment Analysis (DEA) is a static efficiency evaluation method developed by strategists Charnes $e t$ al. (1978). However, the efficiency values of decision-making units calculated by this model are all 1, thus failing to measure the efficiency of decision-making units. In the super-efficiency DEA model proposed by Andersen et al. (1993), the efficiency value can be greater than 1 . This method does not require one to consider the functional relationship between input and output and can directly calculate the efficiency value from the ratio of the weighted sum between the input and output. It can also reveal the profound meaning of economics via performance analysis. Therefore, this paper uses the super-efficiency DEA model to rank the input-output efficiencies of financial inclusion.

When evaluating the efficiency of the $j_{0}$ decision unit, it is excluded from the decision unit set. The planning model used is illustrated in Equation (1).

$$
\bar{P}\left\{\begin{array}{l}
\max h_{j_{0}}=\frac{u^{T} Y_{j_{0}}}{u^{T} X_{j_{0}}}=V \bar{P} \\
\text { s.t. } \\
h_{j}=\frac{u^{T} Y_{j}}{v^{T} X_{j}} \leq 1 \\
j=1,2, \cdots, n \\
j \neq j_{0} \\
v \geq 0, u \geq 0
\end{array}\right.
$$

where $\mathrm{X}_{\mathrm{j}}$ is the input vector of the $j$ decision unit, $\mathrm{Y}_{\mathrm{j}}$ is the output vector of the $j$ decision unit, and $v^{\mathrm{T}}$ and $\mathrm{u}^{\mathrm{T}}$ denote the input-output weight of the $j$ decision unit solved by linear programming. The decision unit is the 17 cities studied (value of n).

\subsection{Malmquist index}

The Malmquist index used in this paper was constructed by Färe et al. (1994) via DEA. It is used to indicate the dynamic change in efficiency, which offers the following useful properties. First, it does not require a priori a distribution hypothesis for the production function and does not require one to estimate parameters, which applies to various forms of input and output (Zhang \& Gui, 2008). Second, the method does not require one to use price information on input and output, rendering it suitable for application with inadequate information

DOI: $10.24818 / 18423264 / 55.2 .21 .03$ 
such as the price of input factors. When the index is greater than 1 , total factor productivity increased in a later period compared relative to an earlier period and otherwise the index is less than 1 as shown in Equation (2).

$$
\begin{aligned}
& M_{t, t+1}=\left[\frac{F^{t}\left(X^{t+1}, Y^{t+1}\right)}{F^{t}\left(X^{t}, Y^{t}\right)} \times \frac{F^{t+1}\left(X^{t+1}, Y^{t+1}\right)}{F^{t+1}\left(X^{t}, Y^{t}\right)}\right]^{\frac{1}{2}} \\
& =\left[\frac{F^{t}\left(X^{t+1}, Y^{t+1}\right)}{F^{t+1}\left(X^{t+1}, Y^{t+1}\right)} \times \frac{F^{t}\left(X^{t}, Y^{t}\right)}{F^{t+1}\left(X^{t}, Y^{t}\right)}\right]^{\frac{1}{2}} \cdot \frac{F^{t+1}\left(X^{t+1}, Y^{t+1}\right)}{F^{t}\left(X^{t}, Y^{t}\right)}=\text { Techch } \times \text { Effch }
\end{aligned}
$$

where $F^{t}\left(X^{t}, Y^{t}\right)$ is the distance function proposed by Shephard (1970); relative to the production frontier of the $t$ period, $F^{t}\left(X^{t}, Y^{t}\right)$ and $F^{t}\left(X^{t+1}, Y^{t+1}\right)$ respectively represent the positions of the input and output of the $t$ and $t+1$ periods; relative to the production frontier of the $t+1$ period, $F^{t+1}\left(X^{t+1}, Y^{t+1}\right)$ and $F^{t+1}\left(X^{t}, Y^{t}\right)$ respectively represent the positions of the input and output of the $t+1$ and $t$ period.

The Malmquist index is also called the total factor productivity change index Tfpch and reflect the change in total factor productivity from the $t$ period to the $t+1$ period. Tfpch can be divided into the technical change index Techch and efficiency change index Effch. Techch represents the frontier movement effect and reflects technological progress and innovation. Effch represents the catch-up effect and reflects the change in organizational management levels. On the premise of variable returns to scale, Effch can be further divided into a pure technical efficiency change index Pech and scale efficiency change index Sech.

\subsection{Tobit regression model}

The Tobit model (Tobit, 1958) is a deletion model in the restricted dependent variable model that can be used for the effective regression analysis of restricted variables (George et al., 2001). When efficiency values are used as explanatory variables, OLS estimation will result in deviation due to a lack of relative data. Therefore, in this paper we use the Tobit regression model to study factors influencing the input-output efficiency of financial inclusion. The Tobit regression model is illustrated in Equation (3).

$$
Y_{i}=\left\{\begin{array}{l}
\beta X_{i}^{T}+\varepsilon_{i}, Y_{i}>0 \\
0, Y_{i} \leq 0
\end{array}\right.
$$

where $Y_{i}$ is the super-efficiency DEA value of the input-output efficiency of financial inclusion, $\beta^{T}$ is the parameter to be estimated and $\varepsilon_{i}$ is the random error term. $X_{i}$ is the independent variable used in this paper to affect the input-output efficiency of financial inclusion, including GDP per capita, urbanization levels, highway density, the urban-rural income gap, government support, education levels, informatization levels and consumption efficiency. The Tobit regression coefficient differs from an ordinary regression. The size of the independent variable coefficient does not reflect the marginal effect on the dependent variable.

DOI: 10.24818/18423264/55.2.21.03 
It can only be judged from a sign whereby an increase in the independent variable causes an increase in dependent variable probability. When the sign is positive, the probability level increases with an increase in the independent variable and vice versa.

\section{Empirical Study}

The development of financial inclusion formally proposed by the Third Plenary Session of the 18th CPC Central Committee was first instituted in November 2013. After the policy was put forward, China actively began to pursue financial inclusion and set up a corresponding statistical index system for financial inclusion. We use the statistical range for 2019 , and our research period runs from 2017-2019. In determining the input-output indexes, we use China's Financial Inclusion Index System for 2019. Forty indexes (as shown in Table 1) are selected from three dimensions, including financial service use, availability, and quality. The input system includes three dimensions: financial basic service input, credit support, and credit construction. Financial basic service (x1) corresponds to x11 to x18 in Table 1, reflecting investment in financial employees, facilities, and service point construction. Credit support (x2) corresponds to $\mathrm{x} 21$ to $\mathrm{x} 26$, reflecting financial institutions' policy support for small and micro-scale enterprises and farmers. Credit construction (x3) corresponds to $\mathrm{x} 31$ to $\mathrm{x} 33$, reflecting the input of credit environment construction. The output system covers dimensions including payment coverage, credit availability, and insurance availability. Payment coverage (y1) corresponds to y11 to y19, reflecting the accounts, cardholding, and digital payment of each person. Credit availability (y2) corresponds to y21 to y211, reflecting the credit situations of small and micro-scale enterprises, agriculturerelated matters, and poverty alleviation. Insurance availability $(\mathrm{y} 3)$ corresponds to y31 to $y 33$, reflecting the popularity of insurance.

Table 1. Index system of financial inclusion

\begin{tabular}{l} 
Dimension \\
\hline Per capita ownership of individual bank settlement accounts (y11). \\
Average ownership of unit bank settlement accounts (y12). \\
Per capita number of bank cards (y13). \\
The number of bank card transactions per capita (y14). \\
The number of non-cash payments per capita (y15). \\
The number of mobile payments per capita (y16). \\
Per capita mobile payment availability (y17). \\
The number of online payments per capita (y18). \\
Per capita online payment availability (y19). \\
Personal consumption loan balance per capita (y21). \\
Personal operating loan balance per capita (y22). \\
Number of credit cards per capita (y23). \\
The proportion of the loan balance of small and micro-scale enterprises (y24). \\
The proportion of the balance of venture guarantee loans (y25). \\
The proportion of the student loan balance (y26). \\
The proportion of the loan balance for affordable housing projects (y27). \\
The proportion of farmers' loan balance (y28). \\
The proportion of farmers with loans (y29). \\
The proportion of the loan balance for agriculture, forestry, animal husbandry and fisheries for \\
\hline
\end{tabular}

DOI: $10.24818 / 18423264 / 55.2 .21 .03$ 
Financial Inclusion in China: Has Input-Output Efficiency Improved?

\begin{tabular}{|c|c|}
\hline Dimension & Index \\
\hline & $\begin{array}{l}\text { rural enterprises and various organizations (y210). } \\
\text { The proportion of the loan balance of rural enterprises and various organizations in supporting } \\
\text { agriculture (y211). } \\
\text { Insurance density (y31). } \\
\text { Agricultural insurance coverage rate (y32). } \\
\text { Life insurance coverage rate (y33). }\end{array}$ \\
\hline Availability & $\begin{array}{l}\text { Number of financial employees per } 10,000 \text { persons }(\mathrm{x} 11) \text {. } \\
\text { The number of bank network points per } 10,000 \text { persons }(\mathrm{x} 12) \text {. } \\
\text { The number of non-financial institutions with financing functions per } 10,000 \text { persons }(\mathrm{x} 13) \text {. } \\
\text { Number of ATMs per } 10,000 \text { persons }(\mathrm{x} 14) \text {. } \\
\text { Number of POS terminals per } 10,000 \text { persons }(\mathrm{x} 15) \text {. } \\
\text { The number of withdrawal service points for farmers per } 10,000 \text { persons in the rural area } \\
(\mathrm{x} 16) \text {. } \\
\text { The number of withdrawals for assisting farmers in rural areas per } 10,000 \text { persons }(\mathrm{x} 17) \text {. } \\
\text { The number of debit cards per } 10,000 \text { persons (x18). }\end{array}$ \\
\hline Quality & $\begin{array}{l}\text { An average credit line of a bank card (x21). } \\
\text { The success rate of loan applications of small and micro-scale enterprises (x22). } \\
\text { The success rate of farmers' loan applications (x23). } \\
\text { The success rate of loan applications of targeted poverty alleviation families (x24). } \\
\text { Small and micro-scale enterprise mortgage loan ratio (x25). } \\
\text { The proportion of farmers' credit loans (x26). } \\
\text { Personal credit file filing rate (x31). } \\
\text { Filing rate of enterprise credit files (x32). } \\
\text { Filing rate of farmers' credit files (x33). }\end{array}$ \\
\hline
\end{tabular}

In constructing the financial inclusion index, Wen et al. (2014) use the analytic hierarchy process to determine the weight of each index. However, due to the subjectivity of this approach, the variation coefficient method is adopted instead. According to the variation coefficient method, when an index has a large variation coefficient, the index plays a larger role in measuring the difference in indexes and the index has a larger weight. First, the variation coefficient $C V_{i}$ of each index in different dimensions in the input-output system is calculated with Equation (4) where $\sigma_{i}$ is the standard deviation of the $i$ index and $\mu_{i}$ is the average value of the $i$ index. Then, the weight of each index is calculated using Equation (5).

$$
\begin{gathered}
C V_{i}=\frac{\sigma_{i}}{\mu_{i}} \\
w_{i}=\frac{C V_{i}}{\sum_{i=1}^{40} C V_{i}}
\end{gathered}
$$

After determining the index weight under each dimension, the dimensional weight is determined according to the number of indexes under each dimension. We hold that more important dimensions have more indexes in China's Financial Inclusion Index System and have greater weight. For example, when there are 17 indexes in the three dimensions ( 8 for the basic input of financial services, 6 for credit support and 3 for credit construction) under the input index system, the weights of the above three dimensions are 8/17, 6/17 and 3/17, respectively. Using the same method, the weights of payment coverage, credit availability and

DOI: 10.24818/18423264/55.2.21.03 
insurance availability under the output system are respectively calculated as 9/23, $11 / 23$ and $3 / 23$.

To eliminate the influence of index data dimensions and maintain the stability of the index, the logarithmic efficacy function method described in the China Digital Financial Inclusion Index System and Index Compilation is used as a reference to normalize the original data. The logarithmic efficacy function equation is as follows.

$$
d_{i j}=\frac{\log x_{i j}-\log x_{i}^{l}}{\log x_{i}^{h}-\log x_{i}^{l}}
$$

where $\mathrm{x}_{\mathrm{ij}}$ is the $i$ index of city $j(\mathrm{j}=1 . .17)$. Regarding the determination of the threshold value in the logarithmic function, to mitigate the influence of extreme values and ensure the longitudinal comparability of indexes, the following processing is applied to the original data: 2017 is selected as the research base period. For the $i$ positive index, the $95 \%$ quantile of the actual value of indexes of all cities in 2017 is taken as the upper limit $\left(x_{i}^{h}\right)$, and the 5\% quantile is taken as the lower limit $\left(x_{i}^{l}\right)$. In addition, data exceeding the upper and lower limits are "truncated" to smooth the index. When the index value is greater than the upper limit, the index value is set as the upper limit and vice versa.

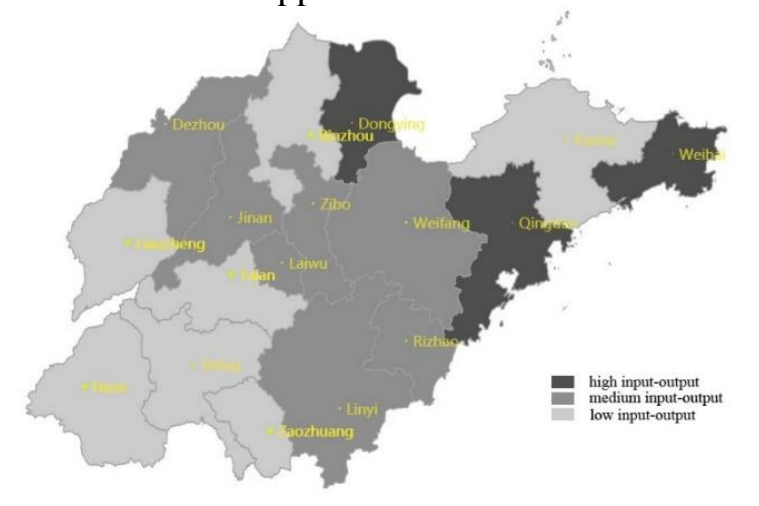

Figure 1. The financial inclusion input-output index for Shandong (2019)

We find from the composite input-output index for 2019 that eastern coastal areas and central and western regions reveal a large gap in levels of economic development in Shandong Province. The eastern coastal areas enjoy natural geographical advantages, and overall levels of economic development are higher than those of other regions. Their relatively diverse economic structure has attracted financial institutions and promoted the development of financial inclusion. The lowest levels of development in the southern region are found in inland areas, which are characterized by a lagging economy, slow adjustment to industrial structures and few attractions for financial institutions, leading to lower levels of inclusive financial development in such areas. Specifically, eastern coastal areas and relatively developed local cities have a high input-output index, including 
Financial Inclusion in China: Has Input-Output Efficiency Improved?

Qingdao, Dongying, and Weihai, meaning that these cities have made positive efforts toward the development of financial inclusion. These three cities benefit from high levels of economic development. Financial institutions are also more willing to provide financial services, promoting the development of local financial inclusion. Jinan, Zibo, and other 5 cities present moderate input-output indexes and consistent levels of economic development. Their economic structures are relatively simple with most depending on agricultural development and characterized by a lack of economic development potential. Jining, Taian, and other 5 cities present low input-output indexes and the fewest financial services relative to other cities, showing that economic development in these cities is relatively low. Most of these cities are resource-based and include a large number of poor counties that rely solely on the development of agriculture and that are experiencing a difficult period of economic transformation.

The super-efficient DEA values of 17 cities in Shandong Province for 2017 to 2019 are calculated using EMS software as shown in Table 2 and Figure 2.

Table 2. Super-efficient DEA values of 17 cities in Shandong for 2017 to 2019

\begin{tabular}{ccccc}
\hline City & $\mathbf{2 0 1 7}$ & $\mathbf{2 0 1 8}$ & $\mathbf{2 0 1 9}$ & Average \\
\hline ZaoZhuang & $236.1 \%$ & $207.7 \%$ & $184.2 \%$ & $209.3 \%$ \\
Liaocheng & $205.3 \%$ & $128.9 \%$ & $141.7 \%$ & $158.6 \%$ \\
Jinan & $132.8 \%$ & $138.2 \%$ & $134.9 \%$ & $135.3 \%$ \\
Dezhou & $112.9 \%$ & $107.6 \%$ & $112.9 \%$ & $111.1 \%$ \\
Jining & $110.2 \%$ & $106.7 \%$ & $111.3 \%$ & $109.4 \%$ \\
Yantai & $115.0 \%$ & $100.0 \%$ & $95.1 \%$ & $103.4 \%$ \\
Taian & $111.9 \%$ & $101.4 \%$ & $82.7 \%$ & $98.7 \%$ \\
Dongying & $104.6 \%$ & $101.7 \%$ & $84.9 \%$ & $97.1 \%$ \\
Heze & $94.0 \%$ & $106.0 \%$ & $86.2 \%$ & $95.4 \%$ \\
Weihai & $87.9 \%$ & $101.6 \%$ & $92.0 \%$ & $93.8 \%$ \\
Qingdao & $86.9 \%$ & $97.3 \%$ & $95.2 \%$ & $93.1 \%$ \\
Binzhou & $61.9 \%$ & $124.4 \%$ & $92.1 \%$ & $92.8 \%$ \\
Weifang & $83.6 \%$ & $80.6 \%$ & $80.4 \%$ & $81.6 \%$ \\
Rizhao & $89.4 \%$ & $73.3 \%$ & $65.0 \%$ & $75.9 \%$ \\
Laiwu & $76.6 \%$ & $64.9 \%$ & $72.1 \%$ & $71.2 \%$ \\
Zibo & $59.9 \%$ & $70.8 \%$ & $66.5 \%$ & $65.7 \%$ \\
Linyi & $57.2 \%$ & $67.2 \%$ & $71.1 \%$ & $65.2 \%$ \\
\hline Average & $107.4 \%$ & $104.6 \%$ & $98.1 \%$ & $103.4 \%$ \\
\hline
\end{tabular}

The average super-efficient DEA value for the 17 cities in Shandong Province is $103.4 \%$. Financial inclusion input-output is effective. In the time dimension, the super-efficient DEA value undergoes downward trends of $107.4 \%$ and $104.6 \%$ in 2017 and 2018, respectively. The super-efficient DEA value decreased to $98.1 \%$ in 2019 . The decrease in the input-output ratio from 2017 to 2018 occurred due to insufficient payment coverage output. However, the decrease in efficiency in 2019 occurred due to the insufficient output of credit availability and especially by the low loan acquisition rate. The low rate was caused by the lack of collateral of small and micro-scale enterprises and agriculture-related and livelihood credit sectors. The super-efficiency DEA value is significantly positively

DOI: 10.24818/18423264/55.2.21.03 
correlated with the input-output ratio, and the correlation coefficient is 0.79 , proving the robustness of conclusions of the super-efficiency DEA model from the perspective of the input-output ratio.

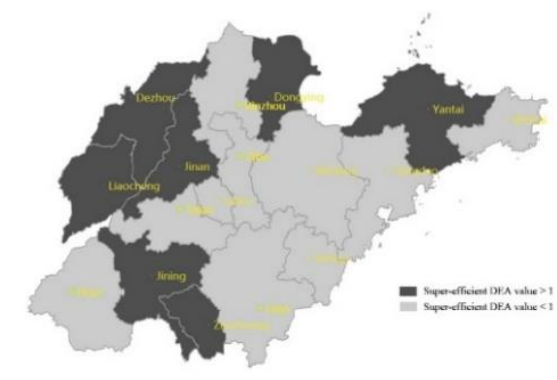

Figure 2-1. Super-efficient DEA values for Shandong (2017)

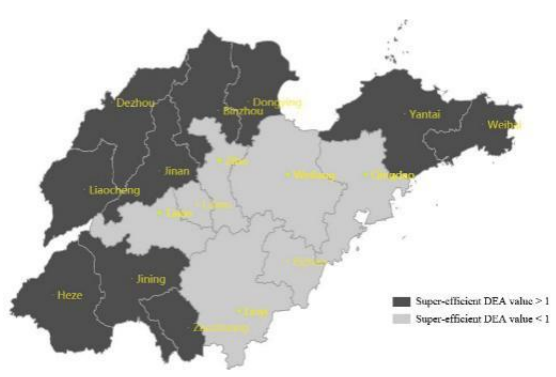

Figure 2-2. Super-efficient DEA values for Shandong (2018)

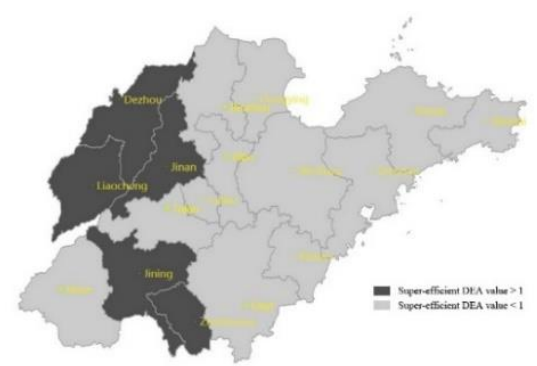

Figure 2-3. Super-efficient DEA values for Shandong (2019)

Regionally, considerable difference in efficiency level are observed between the studied cities. Six cities (Zaozhuang, Liaocheng, Jinan, Dezhou, Jining, Yantai, Taian, and Dongying) have efficient input-output values. The remaining cities have super-efficient DEA values of less than 1 in 2017, indicating that they present inefficient DEA values. Differences in efficiency observed between the cities are mainly caused by a large amount of redundant input. In 2018, more than 11 cities had efficiency values of greater than 1 ; in addition to eight cities with such values in 2017, Heze, Weihai, and Binzhou were added to this list. This phenomenon shows that the implementation of financial inclusion policies can increase super-efficient DEA values in the short term. However, only five cities' efficiency values were greater than 1 , falling far below values measured in 2017 and 2018. This trend shows that the implementation of financial inclusion policies cannot increase super-efficient DEA values over the long term. In other words, the implementation of financial inclusion policies can improve input-output efficiency over the short term and worsen it over the long term, which to some extent reflects the short-sighted nature of government policy-making. 
Financial Inclusion in China: Has Input-Output Efficiency Improved?

Dynamic changes in the input-output efficiency of financial inclusion in 17 cities in Shandong Province were analyzed, and as shown in Table 3, total factor productivity (dynamic efficiency) levels show considerable regional differences. Relative to static efficiency values (super-efficiency DEA), areas with lower financial inclusion input-output indexes exhibit higher levels of dynamic efficiency, faster increases in productivity (e.g., the cities of Jining, Laiwu, Taian, Heze, and Linyi), and total factor productivity values of greater than 1 . This shows that less developed areas are better equipped to develop financial inclusion. This advantage in late development can be attributed to the rapid proliferation of the internet, which has created conditions for improving financial inclusion services in underdeveloped areas (Jiao, 2014). Digital financial technologies made remarkable progress in 2017 and 2018 in Shandong Province with the Digital Financial Inclusion Index respectively reaching 175.69 and 208.35 (Institute of Digital Finance of Peking University, 2019). According to Equation (2), the total factor productivity index is divided into a technical change index and efficiency. Average values of the technical change index for 2017 to 2018 and 2018 to 2019 are 0.83 and 1.02 , respectively. Six of nine cities present technology change indexes of greater than 1 and super-efficiency values of less than 1 from 2018 to 2019. This shows that the progression of technology and innovation is rooted in the development and popularization of internet finance, which can improve the efficiency of financial inclusion in less developed areas.

Table 3. Malmquist indexes and decomposition of 17 cities in Shandong

\begin{tabular}{cccccc|ccccc}
\hline \multirow{2}{*}{ City } & \multicolumn{5}{c}{$\mathbf{2 0 1 7 - 2 0 1 8}$} & \multicolumn{5}{c}{ 2018-2019 } \\
\cline { 2 - 10 } & effch & techch & pech & sech & Tfpch & effch & techch & pech & sech & Tfpch \\
\hline Jinan & 0.77 & 0.82 & 0.71 & 1.09 & 0.63 & 0.93 & 1.05 & 0.94 & 0.99 & 0.98 \\
Qingdao & 1 & 0.749 & 1 & 1 & 0.74 & 1 & 0.91 & 1 & 1 & 0.91 \\
Zibo & 1.12 & 0.97 & 1.10 & 1.02 & 1.08 & 0.98 & 0.99 & 1 & 0.98 & 0.979 \\
Weifang & 1.18 & 0.83 & 1.25 & 0.95 & 0.98 & 0.94 & 1.10 & 0.92 & 1.03 & 1.03 \\
Dongying & 0.96 & 0.87 & 1.01 & 0.96 & 0.84 & 0.99 & 0.99 & 0.98 & 1.02 & 0.99 \\
Yantai & 1 & 0.68 & 1 & 1 & 0.68 & 0.85 & 1.10 & 1 & 0.85 & 0.94 \\
Rizhao & 1 & 0.87 & 1 & 1 & 0.87 & 0.95 & 0.95 & 1 & 0.95 & 0.90 \\
Weihai & 0.82 & 0.82 & 0.83 & 0.99 & 0.67 & 0.89 & 1.11 & 0.89 & 0.99 & 0.99 \\
Jining & 1.14 & 0.70 & 1.14 & 1 & 0.79 & 0.92 & 1.13 & 1 & 0.92 & 1.04 \\
Laiwu & 1 & 0.98 & 1 & 1 & 0.98 & 1 & 1.04 & 1 & 1 & 1.04 \\
Taian & 0.85 & 1.05 & 0.92 & 0.93 & 0.89 & 1.11 & 0.98 & 1.10 & 1.02 & 1.09 \\
Binzhou & 1 & 0.98 & 1 & 1 & 0.98 & 0.83 & 1 & 0.86 & 0.97 & 0.83 \\
Dezhou & 1.62 & 0.85 & 1.61 & 1 & 1.38 & 0.92 & 0.94 & 1 & 0.92 & 0.86 \\
Heze & 1 & 0.73 & 1 & 1 & 0.73 & 1 & 1.08 & 1 & 1 & 1.08 \\
Zaozhuang & 1.06 & 0.96 & 1.06 & 1 & 1.01 & 0.86 & 0.94 & 1 & 0.86 & 0.81 \\
Liaocheng & 1 & 0.86 & 1 & 1 & 0.86 & 1 & 0.99 & 1 & 1 & 0.99 \\
Linyin & 1 & 0.54 & 1 & 1 & 0.54 & 1 & 1.15 & 1 & 1 & 1.15 \\
\hline Average & 1.02 & 0.83 & 1.02 & 0.99 & 0.84 & 0.95 & 1.02 & 0.98 & 0.97 & 0.97 \\
\hline
\end{tabular}

Drawing on studies of factors that influence financial inclusion development levels and resource allocation efficiency (Yang, 2018; Xiong et al.; 2019, Lu et al., 2020), we use GDP per capita, urbanization levels, road density, the urban-rural income gap, government intervention, education levels, information

DOI: 10.24818/18423264/55.2.21.03 
levels, and consumption efficiency as factors that influence financial inclusion input-output efficiency. Among these, GDP per capita measures the level of regional economic development, the urban-rural income gap is the ratio between the disposable income of urban households and rural per capita disposable income, and the urbanization level is the proportion of the urban population of the total population. The two indexes measure the impact of the urban-rural dual structure on the input-output efficiency of financial inclusion where road density refers to the road miles per 100 square kilometers, reflecting the degree of traffic convenience and measuring the level of infrastructure, and government intervention reflects government intervention in agriculturally related financial institutions. To support local agricultural development, the government will intervene in the management strategies of rural financial institutions. Limited by the availability of relevant data, the index uses the proportion of agricultural, forestry and water affairs expenditures of general budget expenditures. The proxy index for education level is the per capita education expenditures of general budget expenditures, reflecting the public's acceptance of financial knowledge and digital finance.

Information technology can reduce the cost of financial inclusion services and improve service efficiency. The number of computers used per 100 people is selected as the proxy index of information level. Consumption efficiency uses the ratio of the total per capita consumption of residents to GDP per capita to reflect the impact of consumption on the input-output efficiency of financial inclusion. The above index data are taken from the Statistical Yearbook of Shandong Province. To eliminate heteroscedasticity and dimensional factors, non-ratio indexes such as GDP per capita, road density and education expenditures per capita are processed logarithmically. Results are shown in Table 4.

Table 4. Regression results for each variable

\begin{tabular}{lrrrr}
\hline Variable & Coefficient & Std. Error & Z-Statistic & Prob. \\
\hline GDP & $2.248^{* * *}$ & 0.6658 & 3.3756 & 0.0007 \\
urban & $-5.035^{* * *}$ & 1.6391 & -3.0719 & 0.0021 \\
road & 0.140 & 0.5945 & 0.2362 & 0.8133 \\
income & -0.203 & 0.1765 & -1.1512 & 0.2497 \\
government & $-5.317^{*}$ & 2.9536 & -1.8002 & 0.0718 \\
education & -2.166 & 0.7290 & -2.9708 & 0.0030 \\
internet & $0.774^{* * *}$ & 0.5412 & 1.4298 & 0.1528 \\
consume & -0.475 & 1.0293 & -0.4616 & 0.6443 \\
\hline \multicolumn{2}{c}{$* *$ and $*$ indicate significance levels of $1 \%$ and 10\%, respectively }
\end{tabular}

$g d p$ in Table 4 represents GDP per capita, urban represents the urban urbanization level, road represents road density, income represents the urban-rural income gap, government represents government intervention, education denotes education level, internet represents the information level, and consume represents consumption efficiency.

The regression results show that the increase in residents' income levels is reflected in per capita GDP, which can promote the improvement of financial

DOI: 10.24818/18423264/55.2.21.03 
Financial Inclusion in China: Has Input-Output Efficiency Improved?

inclusion efficiency. On one hand, an increase in residents' income can effectively stimulate household consumption, thereby increasing the use of payments and payment instruments. On the other hand, an increase in residents' income will enhance the effective demand for financial services and especially for credit and insurance, thus increasing the effective demand for personal loans and the density of insurance. Both of these factors can help improve the output of financial inclusion and efficiency levels.

Since 2013, the urbanization rate of the permanent resident population has increased rapidly in Shandong, exceeding $60 \%$ in 2017. The size of the agricultural population decreased significantly. However, increasing investment in financial inclusion led to resource waste, low levels of production and inefficiency. For instance, the input-output ratio is less than 1 in Qingdao and Zibo, where urbanization rates have reached $72.6 \%$ and $70.3 \%$, respectively. Therefore, there is a negative correlation between the urbanization level and the input and output efficiency of financial inclusion in the regression results. To promote the development of financial inclusion, the government has issued several policies and measures in Shandong that have encouraged financial institutions to support agriculture and small and micro-scale businesses through fiscal awards, subsidies and tax preference policies such as "several opinions on accelerating provincial financial reform and development" since 2013. By the end of 2019, a total of 143,000 rural withdrawals had been set up in rural areas of Shandong with financial infrastructure, rural withdrawal services and mobile payment services covering more than 60,000 villages. Although an increase in fiscal expenditures can encourage financial institutions to increase inputs in financial inclusion over the short term, output is not affected by government financial support. In contrast, investment redundancy will reduce efficiency, which will lead to a negative correlation between the input and output of financial inclusion and government financial support. In recent years, with the development of information technology, the application of non-cash payment instruments in Shandong has increased in addition to usage levels. By the end of 2019, the number of users participating in online payments reached close to 100 million and among these users over $90 \%$ had used mobile payments, greatly promoting the development of financial inclusion. The regression results also indicate that an improvement in informatization levels would improve the input-output efficiency of financial inclusion. In regard to business sustainability, setting up bank branches in rural areas is costly while mobile terminal devices can provide efficient and convenient financial services with marginal costs of close to zero. Further, these devices significantly improve input-output efficiency levels.

Although a relatively high urbanization rate can promote the development of financial inclusion, the level of urbanization is negatively related to the efficiency of financial inclusion input-output. This is mainly the case because target groups of financial inclusion efficiency are located in rural areas. The higher the level of urbanization, the more financial inclusion services are invested in.

DOI: $10.24818 / 18423264 / 55.2 .21 .03$ 
However, under relatively stable demand for financial services and relatively stable output in rural areas, resources allocated to financial inclusion are wasted and low input-output efficiency levels result. For instance, urbanization levels for the cities of Qingdao and Zibo are roughly 70\% while input-output efficiency levels are less than 1 . In analyzing specific input-output structures, we find that these cities show redundancy in inputs. The higher the proportion of government financial support to rural areas, the lower the degree of financial inclusion input-output efficiency. Although an increase in government fiscal expenditures can improve the input level over the short term, the output level is essentially not affected by government fiscal expenditures, which leads to input redundancy and thus reduces efficiency.

As an objective basis of financial inclusion development, the improvement of information levels helps promote the application of mobile terminal equipment payments and effectively improves financial inclusion input-output efficiency. This factor has positive practical significance for rural areas. Considering commercial sustainability, the cost of setting up bank outlets in rural areas is too high, and the marginal cost of providing efficient and convenient mobile financial services through mobile terminals is almost 0 . Therefore, financial inclusion input-output efficiency can be significantly improved.

Per capita GDP, urbanization levels, government intervention, and information levels in the Tobit regression model can significantly affect the inputoutput efficiency of financial inclusion. First, the per capita GDP coefficient is significantly positive. Financial services and product supplies in cities of higher economic development levels are more sufficient and diversified, which can further improve the input-output efficiency of financial inclusion. Second, the urbanization level coefficient is significantly negative. Since the target groups of financial inclusion services are mostly located in rural areas, the higher the urbanization level, the more redundant the input of financial inclusion services is under conditions of relatively stable demand, resulting in low efficiency levels. Third, when the government intervention coefficient is significantly negative, higher levels of government intervention in agricultural financial institutions will have a more negative impact on input-output efficiency. Government intervention has inhibited input-output efficiency. Fourth, the information level coefficient is significantly positive, indicating that the popularization of information technology in rural areas has effectively improved input-output efficiency. Digital financial inclusion services have continuously declined while technologies and innovations of financial inclusion have significantly improved, promoting the development of financial inclusion in rural areas.

\section{Conclusion}

This paper provides a measure of the input-output efficiency of financial inclusion and a comprehensive empirical analysis of influencing factors. We aim to fill a research gap in recent studies by applying the super-efficiency DEA model and Malmquist index based on relevant data taken from China's Financial Inclusion Index System of 17 cities in Shandong Province. The input and output of

DOI: $10.24818 / 18423264 / 55.2 .21 .03$ 
financial inclusion are generally effective, but differences between regions are relatively significant. While the input-output levels of less developed regions are relatively low, due to advantageous effects of the rapid development of internet technologies on lagging regions, the static and dynamic efficiency of financial inclusion input-output in these regions has improved. The implementation of financial inclusion policies can improve input-output efficiency over the short term and worsen it over the long term. Regarding factors that affect financial inclusion input-output efficiency, per capita GDP and information levels can improve inputoutput efficiency while urbanization levels and government support have the opposite effect on efficiency. To address issues such as annual declines in inputoutput efficiency and in the total factor productivity of financial inclusions, the following recommendations are put forward along with Tobit model regression results.

We must change the short-sighted nature of government policy-making and strengthen the construction of information infrastructure in rural areas. It is also imperative that we improve financial inclusion input-output efficiency with the help of financial technologies to increase the supply of financial inclusion services.

\section{ACKNOWLEDGMENTS:}

This study was financially supported by the Social Science Planning Project of Shandong Province(17CKPJ25), the Qingdao Social Science Planning Project(QDSKL1701059), the Humanities and Social Science Research Project of Shandong province's colleges and universities in China(J18RA181).

This work was supported by a grant of the Romanian Ministry of Education and Research, CNCS - UEFISCDI, project number PN-III-P1-1.1TE-2019-2182, within PNCDI III.

\section{REFERENCES}

[1] Hannig, A., Jansen, S. (2010), Financial Inclusion and Financial Stability: Current Policy Issues. ADBI Working Paper, No. 259;

[2] Allen, F., Demirguc-Kunt, A., Klapper, L., Pería, M. S. M. (2012), The Foundations of Financial Inclusion: Understanding Ownership and Use of Formal Accounts. World Bank Policy Research Paper 6290;

[3] Anand, S., Chhikara, K. S. (2013), A Theoretical and Quantitative Analysis of Financial Inclusion and Economic Growth. Management and Labour Studies, 38(1-2): 103-133;

[4] Appleyard, L. (2011), Community Development Finance Institutions (Cdfis): Geographies of Financial Inclusion in the US and UK. Geoforum. 42(02): 250258;

[5] Chen, Y., Sun, Q., Xu, W. (2015), Dynamic and Spatial Convergent of Distribution of China's Inclusive Finance Development. Financial Economics Research, (06): 72-81;

DOI: 10.24818/18423264/55.2.21.03 
Cong Li, Xi-hua LIU, Jiao Wang, Sorana Vatavu, Anda Mihaiela Iosif

[6] Demirgü-Kunt, A., Klapper, L. (2012), Measuring Financial Inclusion: Explaining Variation in the Use of Financial Services across and within Countries; Brookings Papers on Economic Activity, Spring, 279-321;

[7] Sharma, D., Bhattacharya, S., Thukral, S. (2018), Assessment of Financial Inclusive Policy in the Indian Economy. International Journal of Ethics and systems, 34(03): 304-320;

[8] Du, J., Liang, L., Lv, H. (2016), Research on the Efficiency of Regional Science and Technology Finance in China: Based on the Three-Stage DEA Model. Financial Economics Research, (06): 84-92;

[9] Han, R., Melecky, M. (2013), Financial Inclusion for Financial Stability: Access to Bank Deposits and the Growth of Deposits in the Global Financial Crisis; World Bank policy research working paper, No. 6577;

[10] Khan, K., Su, C. W., Moldovan, N. C., Xiong, D. P. (2017), Distinctive Characteristics of the Causality between the PPI and CPI: Evidence from Romania. Economic Computation and Economic Cybernetics Studies and Research, 51(2): 103-123; ASE Publishing;

[11] Mandira, S., Jesim, P. (2011), Financial Inclusion and Development. Journal of International Development, (07):613- 628;

[12] Siddik, Md. N. A., Kabiraj, S. (2018), Does Financial Inclusion Induce Financial Stability? Evidence from a Cross-country Analysis. Australasian Accounting; Business and Finance Journal, 12(1): 34-46;

[13] Su, C. W., Qin, M., Tao, R., Umar, M. (2020), Financial Implications of Fourth Industrial Revolution: Can Bitcoin Improve Prospects of Energy Investment? Technological Forecasting \& Social Change, 158, 120178; [14] Su, C. W., Qin, M., Tao, R., Shao, X.-F., Albu, L. L., Umar, M. (2020), Can Bitcoin Hedge the Risks of Geopolitical Events? Technological Forecasting and Social Change, 159, 120182;

[15] Wang, Y., Zeng, K. (2016), On the Ethnic Basis of Inclusive Finance by Analyzing the History of Economics and Policy. Journal of Financial Research, (02): 37-54;

[16] Xu, Y., Chang, H. L., Lobont, O. R., Su, C. W. (2016), Modeling Heterogeneous Inflation Expectations: Empirical Evidence from Demographic Data? Economic Modelling, (57): 153-163;

[17] Yang, Y. (2015), Measurement of Financial Inclusion Level and Its Impact on Economic Growth - Based on Panel Data of China's Economic Regions from 2005 to 2013. Journal of Finance and Economics, (06): 38-44;

[18] Zhang, C., Wang, C. (2017), Analysis of the Development of Inclusive Financial Development. Economic Relations \& Trade, (09): 114-126;

[19] Zhang, X. X., Liu, L., Su, C. W., Tao, R., Lobont, O. R., Moldovan, N. C. (2019), Bubbles in Agricultural Commodity Markets of China. Complexity, (2019): 1-7. 